\title{
Safety Profile of Upadacitinib up to 3 Years in Psoriatic Arthritis: An Integrated Analysis of Two Pivotal Phase 3 Trials
}

\author{
Gerd R. Burmester (D) - Kevin Winthrop • Ricardo Blanco · Peter Nash • Philippe Goupille • \\ Valderilio F. Azevedo - Carlo Salvarani · Andrea Rubbert-Roth • Elizabeth Lesser • Ralph Lippe • \\ Apinya Lertratanakul · Reva M. Mccaskill · John Liu · Eric M. Ruderman
}

Received: October 26, 2021 / Accepted: November 23, 2021 / Published online: December 30, 2021

(C) The Author(s) 2021

\section{ABSTRACT}

Introduction: This integrated analysis describes the safety profile of upadacitinib, an oral Janus kinase inhibitor, at 15 and $30 \mathrm{mg}$ once daily for up to 3 years of exposure in patients with active psoriatic arthritis (PsA) who had a prior inadequate response or intolerance to $\geq 1$ non-

Supplementary Information The online version contains supplementary material available at https:// doi.org/10.1007/s40744-021-00410-z.

G. R. Burmester $(\bowtie)$

Department of Rheumatology and Clinical Immunology, Charité, Universitätsmedizin Berlin, Charitéplatz 1, 10117 Berlin, Germany

e-mail: gerd.burmester@charite.de

\section{K. Winthrop}

Oregon Health and Science University, GH104,

3375 SW Terwilliger Blvd., Portland, OR 97239, USA

R. Blanco

Hospital University Marques de Valdecilla, IDIVAL, Av. de valedecilla, 25, 39008 Santander, Cantabria, Spain

P. Nash

School of Medicine, Griffith University, Brisbane, QLD 9726, Australia

P. Goupille

University Hospital and CIC1415, Tours, EA 7501, GICC, University of Tours, Tours, France

V. F. Azevedo

Federal University of Paraná, Rua General Carneiro 181, Centro, Curitiba, PR 80000-000, Brazil biologic or biologic disease-modifying antirheumatic drug.

Methods: Safety data were pooled and analyzed from two randomized, placebo-controlled phase 3 trials. Both trials evaluated upadacitinib $15 \mathrm{mg}$ and $30 \mathrm{mg}$ once daily, and one trial also evaluated adalimumab $40 \mathrm{mg}$ every other week. Treatment-emergent adverse events (TEAEs) and laboratory data were summarized for four groups: pooled placebo, pooled upadacitinib $15 \mathrm{mg}$, pooled upadacitinib $30 \mathrm{mg}$, and adalimumab.

\section{Salvarani}

Rheumatology Unit, Azienda USL-IRCCS di Reggio Emilia and University of Modena and Reggio Emilia, Viale Risorgimento 80, 42100 Reggio Emilia, Italy

\section{A. Rubbert-Roth \\ Division of Rheumatology, Cantonal Clinic St. Gallen, Rorschacher Str. 95, 9007 St. Gallen, Switzerland}

E. Lesser · A. Lertratanakul · R. M. Mccaskill · J. Liu AbbVie Inc, 1 North Waukegan Road, North Chicago, IL 60064, USA

\section{R. Lippe}

AbbVie Deutschland $\mathrm{GmbH}$ and Co. KG, Mainzer Str. 81, 65189 Wiesbaden, Germany

\section{E. M. Ruderman}

Northwestern University Feinberg School of Medicine, 420 E Superior St., Chicago, IL 60611, USA 
TEAEs were reported as exposure-adjusted event rates (events per 100 patient-years [E/100 PY]) up to a data cut-off of June 29, 2020.

Results: A total of 2257 patients received $\geq 1$ dose of upadacitinib $15 \mathrm{mg}(N=907)$ or $30 \mathrm{mg}$ $(N=921)$ for 2504.6 PY of exposure or adalimumab $(N=429)$ for 549.7 PY of exposure. Upper respiratory tract infection, nasopharyngitis, and increased creatine phosphokinase (CPK) were the most common TEAEs with upadacitinib. Rates of malignancies, adjudicated major adverse cardiovascular events (MACEs) and venous thromboembolic events (VTEs), and deaths were similar across treatment groups. Rates of herpes zoster (HZ) and opportunistic infections (OI; excluding tuberculosis, HZ, and oral candidiasis) were higher with upadacitinib versus adalimumab. Serious infection, anemia, and CPK elevations were most frequent with upadacitinib $30 \mathrm{mg}$. Potentially clinically significant laboratory abnormalities were uncommon.

Conclusions: Upadacitinib $15 \mathrm{mg}$ and adalimumab had similar safety profiles with the exception of $\mathrm{HZ}$ and OIs, consistent with what was observed in rheumatoid arthritis. Rates of malignancies, MACEs, VTEs, and deaths were comparable among patients receiving upadacitinib and adalimumab. No new safety risks emerged with longer-term exposure to upadacitinib.

Trial Registration Numbers: SELECT-PSA 1: NCT03104400; SELECT-PsA 2: NCT03104374.

\section{PLAIN LANGUAGE SUMMARY}

Psoriatic arthritis is a disease that causes inflammation of the skin and joints. Upadacitinib and adalimumab are medicines that can be used to treat this condition. This analysis combined safety data from two studies of adults with psoriatic arthritis who took upadacitinib, adalimumab, or placebo (no medicine) for up to 3 years. The most common side effects of treatment with upadacitinib were infection and inflammation of the nose and throat and higher amounts of a protein in the blood called creatinine phosphokinase. The total number of cancer cases, heart (cardiovascular) problems, blood clots (embolisms), and deaths were similar across treatment groups, including the placebo (no medicine) group. However, more patients who took upadacitinib than adalimumab or placebo (no medicine) had a painful rash that causes blisters known as herpes zoster (shingles) and infections usually seen in people with a weakened immune system. Most patients had normal blood test results and continued their treatment. Overall, upadacitinib was well tolerated for up to 3 years in patients with psoriatic arthritis. These results agree with what has been found in studies of upadacitinib in patients with rheumatoid arthritis. Safety data of upadacitinib use over a longer time will be reported later.

Keywords: Adalimumab; JAK inhibitor; Psoriatic arthritis; Safety; SELECT-PsA 1; SELECT-PsA 2; Upadacitinib

\section{Key Summary Points}

\section{Why carry out this study?}

Upadacitinib is an oral Janus kinase inhibitor, and adalimumab is a tumor necrosis factor inhibitor for the treatment of psoriatic arthritis (PsA).

This integrated safety analysis of the phase 3 SELECT-PsA 1 and SELECT-PsA 2 clinical trials describes the safety profile of upadacitinib relative to adalimumab for up to 3 years of exposure in patients with PsA.

\section{What was learned from this study?}

Upadacitinib $15 \mathrm{mg}$ once daily and adalimumab $40 \mathrm{mg}$ every other week had similar safety profiles in patients with PsA, except for higher rates of herpes zoster and opportunistic infections with upadacitinib treatment.

No new safety risks emerged with longerterm exposure to upadacitinib, and the safety profile was generally consistent with that of upadacitinib in rheumatoid arthritis. 


\section{INTRODUCTION}

Psoriatic arthritis (PsA) is a chronic inflammatory systemic disease that presents with a variable clinical course. Features of PsA include skin and nail psoriasis, peripheral arthritis, spondylitis, dactylitis, and enthesitis [1]. Advances in understanding and managing PsA have expanded treatment options. Current guidelines recommend treating PsA with conventional synthetic disease-modifying antirheumatic drugs (DMARDs), biologic DMARDs (tumor necrosis factor [TNF] inhibitors, interleukin [IL]-12/23 or IL-17 inhibitors), and targeted synthetic DMARDs (phosphodiesterase-4 inhibitor, Janus kinase inhibitors [JAKi]) [2-4].

Upadacitinib is an oral JAKi engineered for increased selectivity for JAK1 over JAK2, JAK3, and tyrosine kinase 2 [5]. Upadacitinib $15 \mathrm{mg}$ once daily is approved in the United States and Europe to treat moderate-to-severe rheumatoid arthritis (RA) in patients who are intolerant of or have had an inadequate response to methotrexate (MTX) and was recently approved in Europe to treat active PsA and ankylosing spondylitis in patients who are intolerant of or have had an inadequate response to one or more DMARDs or conventional therapy $[6,7]$. The safety and efficacy of upadacitinib for these indications were established in five pivotal clinical trials in RA [8-12], two in PsA [13, 14], and one in ankylosing spondylitis [15]. Improvements in PsA disease activity and safety were demonstrated with upadacitinib through 56 weeks in the phase 3 SELECT-PsA 1 [16] and SELECT-PsA 2 trials [17].

As the therapeutic landscape for PsA evolves, evaluating the long-term safety of treatments is essential to understand benefit-risk profiles and inform patient care. Here, we describe the safety profile of upadacitinib 15 and $30 \mathrm{mg}$ relative to adalimumab as an active comparator in patients with moderately to severely active PsA using integrated data for up to 3 years of treatment from the SELECT-PsA clinical program. Pooled short-term placebo data are also presented to provide context for evaluating adverse events (AEs) with upadacitinib and adalimumab treatment.

\section{METHODS}

\section{Studies}

This integrated safety analysis included data pooled from two randomized, placebo-controlled phase 3 trials, SELECT-PsA 1 (NCT03104400) and SELECT-PsA 2 (NCT03104374) (Supplemental Material: Table S1).

Inclusion criteria for the SELECT-PsA trials have been described previously $[13,14]$. Briefly, patients enrolled in both trials were $\geq 18$ years of age with active PsA and an inadequate response or intolerance to $\geq 1$ non-biologic (SELECT-PsA 1) or biologic (SELECT-PsA 2) DMARD. Patients were excluded if they had a history of cerebrovascular accident or myocardial infarction (MI) within the past 6 months, recurrent or disseminated herpes zoster (HZ), gastrointestinal (GI) perforation or diverticulitis, and malignancy except for successfully treated non-melanoma skin cancer (NMSC) or localized carcinoma in situ of cervix. Additional exclusion criteria are listed in the electronic supplementary material.

The trials were conducted according to the International Conference on Harmonization guidelines, the Declaration of Helsinki principles, and applicable local country regulations. All study-related documents were approved by independent ethics committees and institutional review boards at each site (Supplemental Material: Table S2). All patients gave written informed consent.

\section{Treatments}

Patients were randomly assigned to receive upadacitinib $15 \mathrm{mg}$ once daily, upadacitinib $30 \mathrm{mg}$ once daily, placebo followed by upadacitinib 15 or $30 \mathrm{mg}$ once daily starting at week 24 , or adalimumab $40 \mathrm{mg}$ every other week (SELECT-PsA 1 only). Stable background therapy with non-steroidal anti-inflammatory drugs, acetaminophen, low-potency opiates, oral corticosteroids equivalent to $\leq 10 \mathrm{mg}$ /day of prednisone, and $\leq 2$ non-biologic DMARDs 
was permitted but not required. Patients who did not achieve at least 20\% improvement in tender and swollen joint counts compared with baseline at weeks 12 and 16 could have background therapy adjusted or initiated at week 16 . Beginning at week 36, patients who did not achieve at least 20\% improvement in tender and swollen joint counts compared with baseline at two consecutive visits discontinued study treatment.

\section{Safety Assessments}

All patients who received $\geq 1$ dose of study drug were included in the safety analyses. Upadacitinib $15 \mathrm{mg}$, upadacitinib $30 \mathrm{mg}$, and placebo data were pooled from both SELECTPsA trials. Adalimumab data were from SELECTPsA 1 only. Pooled placebo safety data included patients who received placebo through week 24 . Once these patients switched and started treatment with upadacitinib, safety data reported during the use of upadacitinib were included in the upadacitinib $15 \mathrm{mg}$ and $30 \mathrm{mg}$ analysis sets. The upadacitinib and adalimumab analysis sets included longer-term data with a maximum exposure of up to 3 years.

Safety was assessed by evaluating AEs and laboratory values. Treatment-emergent adverse events (TEAEs) were coded using the Medical Dictionary for Regulatory Activities (MedDRA) version 22.0. A TEAE was defined as an AE with an onset on or after the first dose of study drug and no later than 30 days (upadacitinib and placebo) or 70 days (adalimumab) after the last dose of study drug. Adverse events of special interest (AESIs) were selected because of their increased prevalence in PsA populations and the known or emerging risks reported with JAKi treatment. Severity of AEs were graded by the Common Terminology Criteria for Adverse Events (CTCAE) version 5.0. Potentially clinically significant hematology and chemistry values were graded using the National Cancer Institute's Common Toxicity Criteria version 4.03. Laboratory data entry errors at the study sites were identified as outliers and removed from analyses.
Deaths and cardiovascular (CV) events, including arterial and venous thromboembolic events (VTEs), were blindly adjudicated by an independent, external Cardiovascular Adjudication Committee using pre-specified definitions. GI perforation events were blindly adjudicated by an independent, internal committee using a pre-specified definition. Major adverse cardiovascular events (MACE) included $\mathrm{CV}$ death, non-fatal MI, and non-fatal stroke. VTEs included deep vein thrombosis (DVT) and pulmonary embolism (PE).

\section{Statistical Analyses}

Data were analyzed and summarized for each treatment group. Baseline patient characteristics and treatment exposure were reported descriptively. Exposure was calculated as the date of the last dose minus the date of the first dose plus 1 day for upadacitinib and placebo and 14 days for adalimumab.

Safety data were reported through the data cut-off of June 29, 2020. TEAEs were summarized using MedDRA system organ class and preferred term. Exposure-adjusted event rates (EAERs) were presented as events per 100 patient-years (E/100 PY) based on the treatment received at the time of the AE. Exposure-adjusted incidence rates (EAIRs) were presented as the number of patients with an event per 100 PY (n/100 PY) with exposure censored at the time of the first event. For both EAERs and EAIRs, 95\% confidence intervals (CIs) were calculated using the exact method for the Poisson mean. Mean changes from baseline in laboratory assessments and the proportion of patients with potentially clinically significant laboratory values were summarized.

Risk factors for MACE and VTE were reported qualitatively. Risk factors for $\mathrm{HZ}$ in patients treated with upadacitinib were identified using a univariate Cox regression model. Number needed to harm (NNH), calculated as the reciprocal of the response rate differences, with 95\% CIs were estimated for select AEs at week 24 for upadacitinib versus adalimumab and placebo using data from each individual study; missing data were imputed using non-responder 
imputation. Negative $\mathrm{NNH}$ values indicated that the risk of AEs with upadacitinib was lower than that with adalimumab or placebo; $95 \%$ CIs that included infinity indicated no significant difference in the risk of AEs between upadacitinib and comparator groups.

The standardized incidence ratio (SIR) for malignancy excluding NMSC was computed using age- and gender-specific malignancy data from the US National Cancer Institute Surveillance and Epidemiology and End Results database, Research Data 2000-2015 from 18 registries with 95\% CIs calculated following a Poisson distribution. The standardized mortality ratio (SMR) was computed for the general population using World Health Organization country-, age-, and gender-specific mortality data with 95\% CIs calculated using Byar's approximation.

\section{RESULTS}

\section{Patients}

A total of 2257 patients received $\geq 1$ dose of upadacitinib (15 mg once daily, $n=907 ; 30 \mathrm{mg}$ once daily, $n=921)$ or adalimumab $(n=429)$ for a median duration of 1.3 years in the SELECT-PsA trials. Total PY of exposure were 2504.6 for upadacitinib and 549.7 for adalimumab. Approximately three-quarters of patients received $\geq 1$ year of upadacitinib (15 mg, 73\%; $30 \mathrm{mg}, 72 \%$ ) or adalimumab (72\%) treatment. Nineteen percent of patients received upadacitinib and $11 \%$ received adalimumab for $\geq 2$ years with a maximum exposure of 3 years.

Baseline demographics and disease characteristics were generally balanced across treatment groups (Table 1). Patients had been diagnosed with PsA for an average of 6-8 years, and more than half used concomitant MTX.

\section{Overview of AEs}

Overall, the rates of TEAEs were comparable between upadacitinib $15 \mathrm{mg}$ and adalimumab and numerically higher with upadacitinib
$30 \mathrm{mg}$ (Table 2). Upper respiratory tract infection was the most common TEAE with upadacitinib (Supplemental Material: Table S3). Other common TEAEs ( $\geq 5 \mathrm{E} / 100$ PY) with upadacitinib $15 \mathrm{mg}$ were nasopharyngitis, increased blood creatine phosphokinase (CPK), urinary tract infection, bronchitis, increased alanine transaminase, and hypertension. Acne was reported only with upadacitinib treatment $(15 \mathrm{mg}, 0.9 \mathrm{E} / 100$ PY; $30 \mathrm{mg}, 1.1 \mathrm{E} / 100 \mathrm{PY}$ ). Rates of AEs leading to treatment discontinuation were generally similar across the upadacitinib and adalimumab groups (Table 2). In SELECT-PsA 1, the risk of AEs with upadacitinib $15 \mathrm{mg}$ was comparable with adalimumab based on $\mathrm{NNH}$; the risk of serious AEs with upadacitinib $15 \mathrm{mg}$ was lower but not significantly different than that with adalimumab (as indicated by 95\% CI that include infinity) (Table 3).

Three treatment-emergent deaths were reported with upadacitinib ( $15 \mathrm{mg}, n=1$; $30 \mathrm{mg}, n=2$ ) and identified as non-CV deaths. The causes of deaths were pancytopenia as reported by the investigator (acute respiratory distress syndrome and right pneumothorax per death certificate), COVID-19 infection, and lower airway infection by probable COVID-19. Two non-treatment emergent deaths were reported more than 30 days after the last dose of upadacitinib (15 mg, $n=1 ; 30 \mathrm{mg}, n=1)$. The causes of death were metastatic lung cancer and interstitial lung disease. Mortality rate in the upadacitinib $15 \mathrm{mg}$ group was lower than that of the general population (SMR, 0.14; 95\% CI: 0.03-0.42). Two deaths occurred in the placebo group due to a motor vehicle accident and cardiac arrest. One death occurred in the adalimumab group due to multiple injuries from a motor vehicle accident.

Rates of AEs were largely similar among patients treated with upadacitinib with or without MTX, except for a numerically higher rate of hepatic disorders with MTX combination therapy (15 mg, 17.0 vs. $8.1 \mathrm{E} / 100 \mathrm{PY} ; 30 \mathrm{mg}$, 21.3 vs. 14.9 E/100 PY, respectively) (Supplemental Material: Table S4). 
Table 1 Baseline demographics and disease characteristics of patients receiving one or more doses of study drug

\begin{tabular}{|c|c|c|c|c|}
\hline Characteristic & $\begin{array}{l}\text { PBO } \\
\text { Pooled } \\
N=635 \\
\text { Short-term } \\
\text { data up to } \\
24 \text { weeks }\end{array}$ & $\begin{array}{l}\text { ADA } 40 \mathrm{mg} \text { EOW } \\
N=429 \\
\text { Long-term ADA } \\
\text { (monotherapy or in } \\
\text { combination with MTX/ } \\
\text { other csDMARDs) }\end{array}$ & $\begin{array}{l}\text { UPA } 15 \mathrm{mg} \text { QD } \\
N=907 \\
\text { Long-term UPA } \\
\text { (monotherapy or in } \\
\text { combination with MTX/ } \\
\text { other csDMARDs) }\end{array}$ & $\begin{array}{l}\text { UPA } 30 \mathrm{mg} \text { QD } \\
N=921 \\
\text { Long-term UPA } \\
\text { (monotherapy or in } \\
\text { combination with MTX/ } \\
\text { other csDMARDs) }\end{array}$ \\
\hline Female & $331(52.1)$ & $222(51.7)$ & $478(52.7)$ & $504(54.7)$ \\
\hline $\begin{array}{l}\text { Age, years, mean } \\
\text { (SD) }\end{array}$ & $51.6(12.1)$ & $51.4(12.0)$ & $51.5(12.1)$ & $51.4(12.3)$ \\
\hline \multicolumn{5}{|l|}{ Geographic region } \\
\hline North America & $206(32.4)$ & $79(18.4)$ & $291(32.1)$ & $292(31.7)$ \\
\hline $\begin{array}{l}\text { South/Central } \\
\text { America }\end{array}$ & $85(13.4)$ & $53(12.4)$ & $98(10.8)$ & $108(11.7)$ \\
\hline Western Europe & $63(9.9)$ & $48(11.2)$ & $100(11.0)$ & $98(10.6)$ \\
\hline Eastern Europe & $216(34.0)$ & $192(44.8)$ & $331(36.5)$ & $324(35.2)$ \\
\hline Asia & $46(7.2)$ & $37(8.6)$ & $62(6.8)$ & $66(7.2)$ \\
\hline Other & $19(3.0)$ & $20(4.7)$ & $25(2.8)$ & $33(3.6)$ \\
\hline $\begin{array}{l}\text { Duration since PsA } \\
\text { diagnosis, years, } \\
\text { mean (SD) }\end{array}$ & $7.8(8.6)$ & $5.9(7.1)$ & $7.2(7.8)$ & $7.3(7.7)$ \\
\hline Monotherapy & $188(29.6)$ & $82(19.1)$ & $256(28.2)$ & $276(30.0)$ \\
\hline \multicolumn{5}{|c|}{ Concomitant non-biologic DMARD at baseline } \\
\hline MTX alone & $342(53.9)$ & $270(62.9)$ & $515(56.8)$ & $487(52.9)$ \\
\hline $\begin{array}{l}\text { MTX + another } \\
\text { non-biologic } \\
\text { DMARD }\end{array}$ & $33(5.2)$ & $16(3.7)$ & $37(4.1)$ & $48(5.2)$ \\
\hline $\begin{array}{l}\text { Non-biologic } \\
\text { DMARD other } \\
\text { than MTX }\end{array}$ & $72(11.3)$ & $61(14.2)$ & $99(10.9)$ & $110(11.9)$ \\
\hline RF status positive & $26(4.1)$ & $13(3.0)$ & $38(4.2)$ & $42(4.6)$ \\
\hline $\begin{array}{l}\text { ACPA status } \\
\text { positive }\end{array}$ & $26(4.1)$ & $11(2.6)$ & $27(3.0)$ & $32(3.5)$ \\
\hline $\begin{array}{c}\text { History of } \mathrm{HZ} \\
\text { vaccination }\end{array}$ & $26(4.1)$ & $14(3.3)$ & $35(3.9)$ & $41(4.5)$ \\
\hline History of VTE & $18(2.8)$ & $3(0.7)$ & $23(2.5)$ & $15(1.6)$ \\
\hline History of IBD & $11(1.7)$ & $4(0.9)$ & $14(1.5)$ & $7(0.8)$ \\
\hline History of uveitis & $3(0.5)$ & $2(0.5)$ & $3(0.3)$ & $2(0.2)$ \\
\hline
\end{tabular}


Table 1 continued

\begin{tabular}{|c|c|c|c|c|}
\hline Characteristic & $\begin{array}{l}\text { PBO } \\
\text { Pooled } \\
N=635 \\
\text { Short-term } \\
\text { data up to } \\
24 \text { weeks }\end{array}$ & $\begin{array}{l}\text { ADA } 40 \mathrm{mg} \text { EOW } \\
N=429 \\
\text { Long-term ADA } \\
\text { (monotherapy or in } \\
\text { combination with MTX/ } \\
\text { other csDMARDs) }\end{array}$ & $\begin{array}{l}\text { UPA } 15 \mathrm{mg} \text { QD } \\
N=907 \\
\text { Long-term UPA } \\
\text { (monotherapy or in } \\
\text { combination with MTX/ } \\
\text { other csDMARDs) }\end{array}$ & $\begin{array}{l}\text { UPA } 30 \mathrm{mg} \text { QD } \\
N=921 \\
\text { Long-term UPA } \\
\text { (monotherapy or in } \\
\text { combination with MTX/ } \\
\text { other csDMARDs) }\end{array}$ \\
\hline \multicolumn{5}{|c|}{$\mathrm{CV}$ risk factors at baseline } \\
\hline Hypertension & $284(44.7)$ & $179(41.7)$ & $402(44.3)$ & $375(40.7)$ \\
\hline Diabetes mellitus & $89(14.0)$ & $47(11.0)$ & $118(13.0)$ & $126(13.7)$ \\
\hline $\begin{array}{l}\text { Tobacco/nicotine } \\
\text { use } \\
\text { (current }+ \text { former) }\end{array}$ & $261(41.1)$ & $163(38.0)$ & $385(42.4)$ & $393(42.7)$ \\
\hline $\begin{array}{l}\text { Elevated LDL-C } \\
(\geq 3.36 \mathrm{mmol} / \mathrm{l})\end{array}$ & $177(27.9)$ & $121(28.2)$ & $253(27.9)$ & $265(28.8)$ \\
\hline $\begin{array}{l}\text { Lowered HDL-C } \\
(\leq 1.55 \mathrm{mmol} / \mathrm{l})\end{array}$ & $455(71.7)$ & $306(71.3)$ & $637(70.2)$ & $649(70.5)$ \\
\hline Statin use & $88(13.9)$ & $42(9.8)$ & $123(13.6)$ & $124(13.5)$ \\
\hline
\end{tabular}

Values are $n$ (\%) unless noted. UPA $15 \mathrm{mg}$ and UPA $30 \mathrm{mg}$ QD groups include patients who were originally assigned to UPA and patients originally assigned to PBO who switched to UPA at week 24

$A C P A$ anti-cyclic citrullinated peptide antibodies, $A D A$ adalimumab, $c s D M A R D$ conventional synthetic disease-modifying antirheumatic drug, $C V$ cardiovascular, $D M A R D$ disease-modifying antirheumatic drug, $E O W$ every other week, $H D L-C$ high-density lipoprotein cholesterol, $H Z$ herpes zoster, $I B D$ inflammatory bowel disease, $L D L-C$ low-density lipoprotein cholesterol, $M T X$ methotrexate, $P B O$ placebo, $P_{S} A$ psoriatic arthritis, $Q D$ once daily, $R F$ rheumatoid factor, $S D$ standard deviation, $U P A$ upadacitinib, $V T E$ venous thromboembolism

\section{AEs of Special Interest}

AESIs are summarized as EAERs (Fig. 1) and EAIRs (Supplemental Material: Figure S1) by treatment group.

Rates of serious infection were numerically higher with upadacitinib $30 \mathrm{mg}(5.2 \mathrm{E} / 100 \mathrm{PY})$ compared to upadacitinib $15 \mathrm{mg}(2.3 \mathrm{E} / 100 \mathrm{PY})$ and adalimumab (1.3 E/100 PY) (Fig. 1a). Serious infection generally occurred more frequently in older versus younger patients (aged $\geq 75$ years: upadacitinib $15 \mathrm{mg}, \quad 9.6$ E/100 PY; upadacitinib $30 \mathrm{mg}, 4.2 \mathrm{E} / 100 \mathrm{PY}$; adalimumab, 0 E/100 PY vs. $\geq 65$ to $<75$ years: 3.9 E/100 PY, 5.5 E/100 PY, and 3.6 E/100 PY, respectively vs. $<65$ years: $2.0 \mathrm{E} / 100$ PY, 5.1 E/100 PY, and 0.9 E/100 PY, respectively). Pneumonia was the most common serious infection observed in $2 \%$ of patients treated with upadacitinib (six events with $15 \mathrm{mg}, 0.5 \mathrm{E} / 100 \mathrm{PY} ; 12$ events with $30 \mathrm{mg}, 1.0$ E/100 PY). Opportunistic infections excluding tuberculosis (TB), HZ, and oral candidiasis were reported only with upadacitinib treatment, with numerically higher rates observed for patients receiving upadacitinib $30 \mathrm{mg}$ versus $15 \mathrm{mg}$ (Fig. 1b and Supplemental Material: Table S5). Mucosal candida infection was the most common opportunistic infection. Three events (0.2 E/100 PY) of serious opportunistic infections occurred with upadacitinib $30 \mathrm{mg}$ (one patient with both cytomegalovirus infection and Pneumocystis jirovecii pneumonia; one patient with Pneumocystis jirovecii pneumonia), and none occurred with upadacitinib $15 \mathrm{mg}$. 
Table 2 Treatment-emergent adverse events in any upadacitinib, adalimumab, and placebo treatment groups

\begin{tabular}{|c|c|c|c|c|}
\hline $\begin{array}{l}\text { E/100 PY }(95 \% \\
\text { CI), unless stated } \\
\text { otherwise }\end{array}$ & $\begin{array}{l}\text { PBO Pooled } \\
N=635 \\
\text { Short-term } \\
\text { data up to } \\
24 \text { weeks }\end{array}$ & $\begin{array}{l}\text { ADA } 40 \text { mg EOW } \\
N=429 \\
\text { Long-term ADA } \\
\text { (monotherapy or in } \\
\text { combination with } \\
\text { MTX/other } \\
\text { csDMARDs) } \\
\text { Mean exposure: } \\
67 \text { weeks }\end{array}$ & $\begin{array}{l}\text { UPA } 15 \mathrm{mg} \text { QD } \\
N=907 \\
\text { Long-term UPA } \\
\text { (monotherapy or in } \\
\text { combination with } \\
\text { MTX/other } \\
\text { csDMARDs) } \\
\text { Mean exposure: } \\
72 \text { weeks }\end{array}$ & $\begin{array}{l}\text { UPA } 30 \text { mg QD } \\
N=921 \\
\text { Long-term UPA } \\
\text { (monotherapy or in } \\
\text { combination with } \\
\text { MTX/other } \\
\text { csDMARDs) } \\
\text { Mean exposure: } \\
71 \text { weeks }\end{array}$ \\
\hline $\begin{array}{l}\text { Total PY of } \\
\text { exposure, years }\end{array}$ & 268.7 & 549.7 & 1247.2 & 1257.4 \\
\hline $\begin{array}{l}\text { Median exposure, } \\
\text { days (range) }\end{array}$ & $168.0(1-183)$ & $477.0(14-1065)$ & $482.0(1-1083)$ & $482.0(1-1077)$ \\
\hline Any AE & $352.1(330.0-375.2)$ & $286.5(272.5-301.0)$ & $263.9(254.9-273.0)$ & $321.5(311.7-331.6)$ \\
\hline Any SAE & $8.2(5.1-12.4)$ & $9.6(7.2-12.6)$ & $10.3(8.6-12.3)$ & $13.2(11.3-15.4)$ \\
\hline $\begin{array}{c}\text { Any AE leading to } \\
\text { discontinuation }\end{array}$ & $12.3(8.5-17.2)$ & $7.8(5.7-10.5)$ & $6.7(5.3-8.2)$ & $7.8(6.3-9.5)$ \\
\hline Deaths ${ }^{\mathrm{a}}$ & $0.7(0.1-2.7)$ & $0.2(0.0-1.0)$ & $0.2(0.0-0.6)$ & $0.2(0.0-0.7)$ \\
\hline
\end{tabular}

UPA $15 \mathrm{mg}$ and UPA $30 \mathrm{mg}$ QD groups include patients who were originally assigned to UPA and patients originally assigned to PBO who switched to UPA at week 24

${ }^{a}$ Deaths included non-treatment emergent deaths that occurred $>30$ days after the last dose of study drug (UPA 15 mg, 1; UPA $30 \mathrm{mg}, 1)$

$A D A$ adalimumab, $A E$ adverse event, $C I$ confidence interval, csDMARD conventional synthetic disease-modifying antirheumatic drug, E/100 PY event per 100 patient-years, $E O W$ every other week, $M T X$ methotrexate, $P B O$ placebo, $P Y$ patient year, $Q D$ once daily, $S A E$ serious adverse event, $U P A$ upadacitinib

No active TB was reported in the SELECT-PsA program.

Rates of $\mathrm{HZ}$ were numerically greater with upadacitinib versus adalimumab; events were reported more frequently with upadacitinib $30 \mathrm{mg}$ than $15 \mathrm{mg}$ (Fig. 1c). Most cases of HZ in the upadacitinib $15 \mathrm{mg}$ and $30 \mathrm{mg}$ groups were non-serious (96\% and 93\%) and involved one $(67 \%$ and $65 \%)$ or two (19\% and $21 \%)$ dermatomes. No events of central nervous system or non-cutaneous involvement were reported. All patients who developed $\mathrm{HZ}$ in the upadacitinib $15 \mathrm{mg}$ group and most in the upadacitinib $30 \mathrm{mg}$ group (96\%) initiated therapy for HZ. Upadacitinib treatment was temporarily interrupted in two-thirds $(67 \%)$ of
$\mathrm{HZ}$ events. Few patients $(<1 \%)$ permanently discontinued upadacitinib due to HZ: two in the $15 \mathrm{mg}$ and four in the $30 \mathrm{mg}$ groups. Ophthalmic involvement of the periorbital skin was seen in two patients treated with upadacitinib (one with $15 \mathrm{mg}$, one with $30 \mathrm{mg}$ ). One case of severe disseminated cutaneous HZ was reported with upadacitinib $30 \mathrm{mg}$. Among those treated with upadacitinib $15 \mathrm{mg}$, the risk of HZ was higher in Asian patients and increased with age (Supplemental Material: Table S6). Across treatment groups, about $3-5 \%$ of patients had a history of $\mathrm{HZ}$ vaccination at baseline, and none of these patients developed HZ. 
Table 3 Number needed to harm for adverse events at week 24 in the SELECT-PsA trials

\begin{tabular}{|c|c|c|c|}
\hline \multirow[t]{2}{*}{ NNH (95\% CI) } & \multicolumn{2}{|l|}{ SELECT-PsA 1} & \multirow{2}{*}{$\begin{array}{l}\text { SELECT-PsA } 2 \\
\text { UPA } 15 \mathrm{mg} \text { QD versus } \\
\text { PBO }\end{array}$} \\
\hline & $\begin{array}{l}\text { UPA } 15 \mathrm{mg} \text { QD versus } \\
\text { PBO }\end{array}$ & $\begin{array}{l}\text { UPA } 15 \mathrm{mg} \text { QD versus ADA } \\
40 \mathrm{mg} \text { EOW }\end{array}$ & \\
\hline Any AE & $14(7-119)$ & 48 (ns) & 63 (ns) \\
\hline Any SAE & 500 (ns) & $-250(n s)$ & $26(14-582)$ \\
\hline $\begin{array}{l}\text { Any } \mathrm{AE} \text { leading to } \\
\text { discontinuation }\end{array}$ & $-1000(n s)$ & $-48(n s)$ & 53 (ns) \\
\hline Serious infection & 333 (ns) & 200 (ns) & N/A \\
\hline $\mathrm{HZ}$ & 500 (ns) & $111(\mathrm{~ns})$ & 200 (ns) \\
\hline VTE & -500 (ns) & -200 (ns) & 200 (ns) \\
\hline MACE & -500 (ns) & -200 (ns) & 200 (ns) \\
\hline
\end{tabular}

UPA $15 \mathrm{mg}$ group includes patients who were originally assigned to UPA and patients originally assigned to PBO who switched to UPA at week 24

Negative values indicate that the risk of AEs with UPA was lower than that with the comparator (PBO or ADA)

$95 \%$ CIs that include infinity were presented as $n s$ if there was no significant difference in the risk of AEs between UPA and the comparator $(\mathrm{PBO}$ or $\mathrm{ADA})$

$\mathrm{N} / \mathrm{A}$ indicates that the NNH was undefined, and the risk of serious infection was the same with UPA vs. PBO

Missing data were imputed using non-responder imputation.

$A D A$ adalimumab, $A E$ adverse event, $C I$ confidence interval, $E O W$ every other week, $H Z$ herpes zoster, $M A C E$ major adverse cardiovascular events, $N / A$ not applicable, $N N H$ number needed to harm, $n s$ non-significant, $P B O$ placebo, $Q D$ once daily, $S A E$ serious adverse event, $U P A$ upadacitinib, $V T E$ venous thromboembolism

Malignancies excluding NMSC were reported at similar rates across the upadacitinib and adalimumab groups (Fig. 1d and Supplemental Material: Table S5). No notable patterns of malignancies were observed, and the types of malignancies reflected those expected in a PsA population; all but one malignancy was reported in a single patient (prostate cancer was reported in two patients). The age- and genderadjusted SIR for malignancies excluding NMSC were 1.01 (95\% CI $0.46-1.91)$ for upadacitinib $15 \mathrm{mg}$ and 1.11 (95\% CI $0.53-2.03)$ for upadacitinib $30 \mathrm{mg}$, suggesting no increased risk in patients treated with upadacitinib compared to the general population. Similar rates of NMSC were also reported across the upadacitinib and adalimumab groups (Fig. 1e). None of the NMSC events were serious; one event in each of the two upadacitinib groups led to treatment discontinuation. Most NMSC events with upadacitinib were basal cell carcinomas (seven events with $15 \mathrm{mg}, 0.6 \mathrm{E} / 100 \mathrm{PY}$; five events with $30 \mathrm{mg}, 0.4 \mathrm{E} / 100 \mathrm{PY})$. Two transient abnormal lymphocyte morphology events were observed with upadacitinib $15 \mathrm{mg}$; no confirmed cases of lymphoma were reported in the SELECT-PsA program.

Rates of adjudicated MACE and VTE were comparable across treatment groups, and all events were non-fatal (Fig. $1 \mathrm{f}-\mathrm{g}$ and Supplemental Material: Table S7). Two patients had MI and two had stroke with upadacitinib $15 \mathrm{mg}$; two patients had MI and one had stroke with upadacitinib $30 \mathrm{mg}$; and two patients had stroke and one had MI with adalimumab. Two patients had PE, one had DVT, and one had concurrent DVT and PE with upadacitinib $15 \mathrm{mg}$; three patients had PE with upadacitinib $30 \mathrm{mg}$; and two patients had DVT with adalimumab. All patients on upadacitinib who experienced an adjudicated MACE or VTE had $\geq 1$ risk factor at baseline, including hypertension, smoking, dyslipidemia, high body mass index, history of VTE, or thrombosis. No dose 

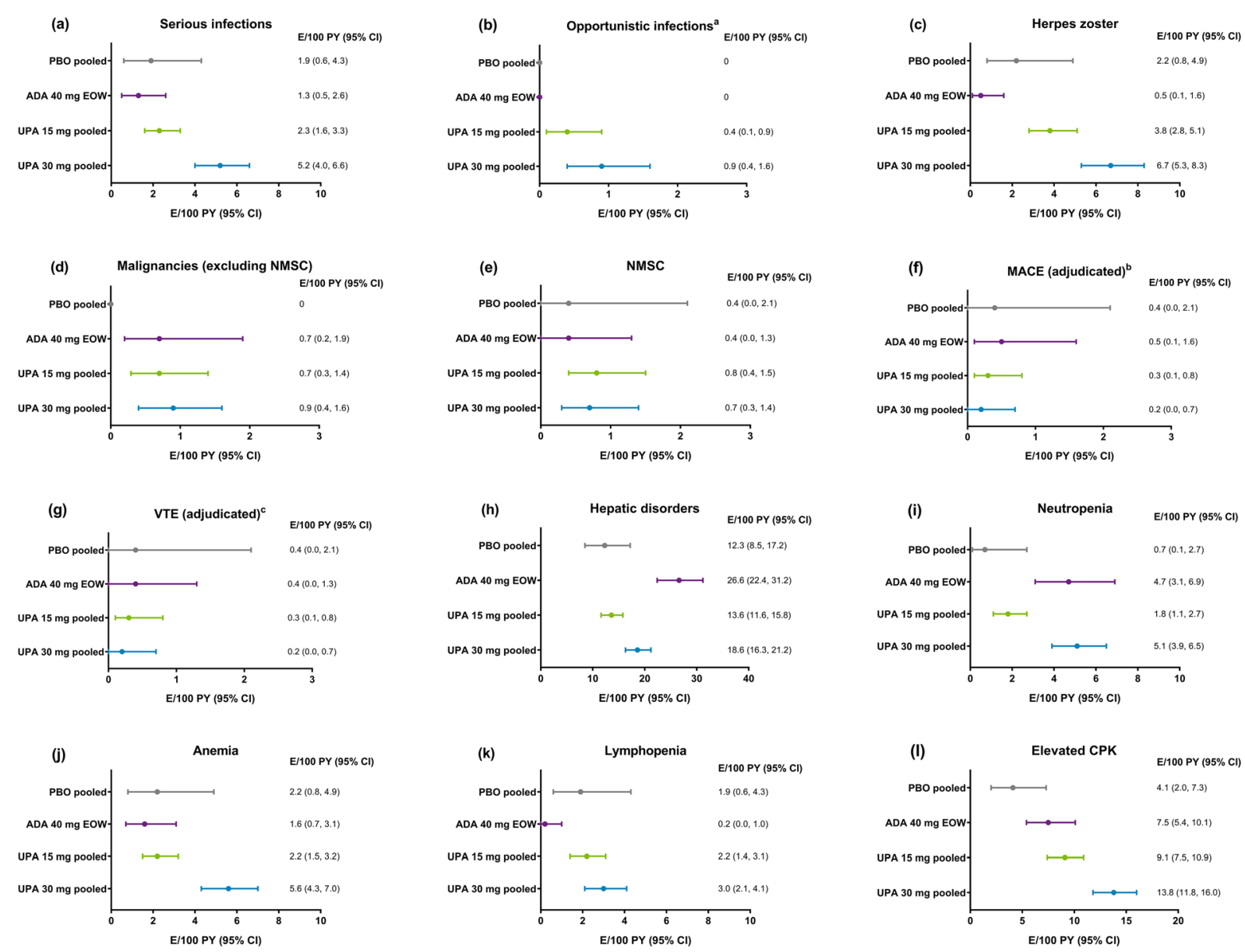

Fig. 1 Event rates per 100 patient years for adverse events of special interest $(\mathbf{a}-1)$. Events are presented as exposureadjusted event rates per 100 patient-years (E/100 PY), calculated as the total number of events adjusted for total exposure to UPA, ADA, or PBO. UPA $15 \mathrm{mg}$ and UPA $30 \mathrm{mg}$ QD groups include patients who were originally assigned to UPA and patients originally assigned to PBO who switched to UPA at week 24. ${ }^{a}$ Opportunistic infections excluded tuberculosis, herpes zoster, and oral

dependency was observed for adjudicated MACE or VTE with upadacitinib.

One adjudicated GI (gastric ulcer) perforation $(<0.1 \mathrm{E} / 100 \mathrm{PY})$, occurring 289 days after initiating upadacitinib $15 \mathrm{mg}$, was identified in a patient with concomitant use of non-steroidal anti-inflammatory drugs.

Rates of hepatic disorders were comparable between both doses of upadacitinib and numerically higher with adalimumab (Fig. 1h). Hepatic disorders were mostly transient, non- candidiasis. ${ }^{\mathrm{b}} \mathrm{MACE}$ was defined as $\mathrm{CV}$ death, non-fatal MI, and non-fatal stroke. ${ }^{c}$ VTE was defined as deep vein thrombosis and pulmonary embolism. $A D A$ adalimumab, $C P K$ creatine phosphokinase, E/100 PY event per 100 patient-years, $E O W$ every other week, $M A C E$ major adverse cardiovascular event, $M I$ myocardial infarction, NMSC non-melanoma skin cancer, $P B O$ placebo, UPA upadacitinib, $V T E$ venous thromboembolism

serious transaminase increases. Serious hepatic disorders were reported in two patients treated with upadacitinib $30 \mathrm{mg}$ (one each with druginduced liver injury and hemangioma of the liver, $0.2 \mathrm{E} / 100 \mathrm{PY})$ and two treated with adalimumab (one each with hepatic encephalopathy and jaundice, $0.4 \mathrm{E} / 100 \mathrm{PY}$ ). The patient receiving upadacitinib $30 \mathrm{mg}$ who experienced drug-induced liver injury had a medical history of psoriasis vulgaris, fatty liver, hyperlipidemia, and a body mass index of 36. Except for 
increased liver transaminases, the patient was asymptomatic with normal international normalized ratio and total bilirubin levels.

Rates of neutropenia were similar for upadacitinib $30 \mathrm{mg}$ and adalimumab and lower with upadacitinib $15 \mathrm{mg}$ (Fig. 1i). Anemia was more frequent with upadacitinib $30 \mathrm{mg}$ than other treatment groups (Fig. 1j). Rates of lymphopenia were similar with both doses of upadacitinib and lower with adalimumab (Fig. 1k). Events of neutropenia, anemia, and lymphopenia were generally mild or moderate, non-serious, and rarely led to treatment discontinuation. Rates of CPK elevations were comparable between upadacitinib $15 \mathrm{mg}$ and adalimumab and higher with upadacitinib $30 \mathrm{mg}$ (Fig. 11). No rhabdomyolysis was reported.

Events of inflammatory bowel disease (IBD) and uveitis were rare. Three events of IBD were reported with upadacitinib $15 \mathrm{mg}(0.2 \mathrm{E} / 100 \mathrm{PY}$; Crohn's disease flare, worsening of pre-existing colitis, and new event of colitis), two with upadacitinib $30 \mathrm{mg}$ (0.2 E/100 PY; new events of acute descending colitis confined to the splenic flexure and localized mild inflammation in cecum secondary to colitis), and one with placebo (0.4 E/100 PY; Crohn's disease flare). Two events of uveitis occurred with placebo (0.7 E/100 PY; one event in a patient with a history of uveitis), one with upadacitinib $15 \mathrm{mg}(<0.1$ $\mathrm{E} / 100 \mathrm{PY})$, and one with adalimumab (0.2 E/100 PY; event occurred in a patient with a history of uveitis).

\section{Laboratory Assessments}

Overall, clinically meaningful lab abnormalities, defined as CTCAE grade 3 or grade 4 , were generally infrequent (Table 4). Grade 3/4 decreases in lymphocytes and increases in CPK were more frequent with upadacitinib versus adalimumab or placebo; these laboratory changes were more common with upadacitinib $30 \mathrm{mg}$ than $15 \mathrm{mg}$. The proportions of patients experiencing grade 3 decreases in neutrophils and increases in aspartate aminotransferase were similar between upadacitinib $15 \mathrm{mg}$ and adalimumab and greater with upadacitinib
$30 \mathrm{mg}$. Most individual changes in hemoglobin, platelet, neutrophil, and lymphocyte levels were transient, generally returned to baseline levels with continued treatment, and did not lead to treatment discontinuation (Fig. 2a-d). No Hy's law cases were reported in the SELECTPsA program.

\section{DISCUSSION}

In this integrated analysis of the SELECT-PsA clinical trial program, the overall safety profile of upadacitinib in PsA was generally consistent with that observed with upadacitinib in RA [18], with no new or unexpected safety risks identified. The safety profiles of upadacitinib $15 \mathrm{mg}$ and adalimumab were similar, and the rates of most AEs were numerically higher with upadacitinib $30 \mathrm{mg}$ than upadacitinib $15 \mathrm{mg}$ or adalimumab.

Lower rates of serious infection, $\mathrm{HZ}$, neutropenia, anemia, and CPK elevations were observed with upadacitinib $15 \mathrm{mg}$ versus $30 \mathrm{mg}$. The EAIR of serious infections, a known risk of immunomodulatory agents $[19,20]$, with upadacitinib $15 \mathrm{mg}$ (2.2/100 PY) was comparable with adalimumab (1.1/100 PY), and that reported in integrated safety analyses of other marketed advanced PsA therapies with up to 3 years of exposure (1.3-1.7/100 PY) [21-23].

Among patients with rheumatic disease, $\mathrm{HZ}$ has emerged as a safety signal with JAKi treatment [24], which may be attributed to inhibition of key anti-viral cytokines, interferon (IFN) and IL-15 [25]. Higher rates of HZ were found with upadacitinib versus adalimumab and placebo, but most cases were non-serious involving a single dermatome. Similar to previous findings with other JAKi $[26,27]$, higher $\mathrm{HZ}$ rates with upadacitinib were observed for those who were Asian or older. Prior $\mathrm{HZ}$ vaccination in the SELECT-PsA clinical program was low $(<5 \%)$, consistent with that reported in studies of baricitinib (4\%) [26] and tofacitinib $(<10 \%)$ [28]. Most patients temporarily withdrew upadacitinib treatment during their $\mathrm{HZ}$ event. According to the product label, temporary interruption of upadacitinib is recommended until the $\mathrm{HZ}$ event resolves, along with close 
Table 4 Proportion of patients with potentially clinically significant laboratory values

\begin{tabular}{|c|c|c|c|c|}
\hline $\begin{array}{l}\text { Parameter, } \\
n / N(\%)\end{array}$ & $\begin{array}{l}\text { PBO } \\
\text { Pooled } \\
N=635 \\
\text { Short-term } \\
\text { data up to } \\
24 \text { weeks }\end{array}$ & $\begin{array}{l}\text { ADA } 40 \text { mg EOW } \\
N=429 \\
\text { Long-term ADA } \\
\text { (monotherapy or in } \\
\text { combination with MTX/ } \\
\text { other csDMARDs) } \\
\text { Mean exposure: } 67 \text { weeks }\end{array}$ & $\begin{array}{l}\text { UPA } 15 \mathrm{mg} \text { QD } \\
N=907 \\
\text { Long-term UPA } \\
\text { (monotherapy or in } \\
\text { combination with MTX/ } \\
\text { other csDMARDs) } \\
\text { Mean exposure: } 72 \text { weeks }\end{array}$ & $\begin{array}{l}\text { UPA } 30 \mathrm{mg} \text { QD } \\
N=921 \\
\text { Long-term UPA } \\
\text { (monotherapy or in } \\
\text { combination with MTX/ } \\
\text { other csDMARDs) } \\
\text { Mean exposure: } 71 \text { weeks }\end{array}$ \\
\hline \multicolumn{5}{|l|}{ Hemoglobin $(\mathrm{g} / \mathrm{l})$} \\
\hline Grade $3(<80)$ & $0 / 627$ & $2 / 427(0.5)$ & $2 / 901(0.2)$ & $5 / 918(0.5)$ \\
\hline \multicolumn{5}{|l|}{ Platelets $\left(\times 10^{9} / \mathrm{l}\right)$} \\
\hline $\begin{array}{l}\text { Grade } 3(25 \\
\text { to }<50)\end{array}$ & $0 / 625$ & $0 / 427$ & $0 / 901$ & $1 / 918(0.1)$ \\
\hline Grade $4(<25)$ & $0 / 625$ & $0 / 427$ & $1 / 901(0.1)$ & $1 / 918(0.1)$ \\
\hline \multicolumn{5}{|l|}{ Neutrophils $\left(\times 10^{9} / \mathrm{l}\right)$} \\
\hline $\begin{array}{l}\text { Grade } 3(0.5 \\
\text { to }<1.0)\end{array}$ & $2 / 627(0.3)$ & $3 / 426(0.7)$ & 7/901 (0.8) & $19 / 918(2.1)$ \\
\hline Grade $4(<0.5)$ & $0 / 627$ & $0 / 426$ & $0 / 901$ & $0 / 918$ \\
\hline \multicolumn{5}{|c|}{ Lymphocytes $\left(\times 10^{9} / 1\right)$} \\
\hline $\begin{array}{l}\text { Grade } 3(0.2 \\
\text { to }<0.5)\end{array}$ & $1 / 627(0.2)$ & $0 / 426$ & $15 / 901(1.7)$ & $29 / 918(3.2)$ \\
\hline Grade $4(<0.2)$ & $0 / 627$ & $0 / 426$ & $0 / 901$ & $1 / 918(0.1)$ \\
\hline \multicolumn{5}{|l|}{ Leukocytes $\left(\times 10^{9} / 1\right)$} \\
\hline $\begin{array}{l}\text { Grade } 3(1.0 \\
\text { to }<2.0)\end{array}$ & $1 / 627(0.2)$ & $0 / 427$ & $0 / 901$ & 4/918 (0.4) \\
\hline Grade $4(<1.0)$ & $0 / 627$ & $0 / 427$ & $0 / 901$ & $1 / 918(0.1)$ \\
\hline \multicolumn{5}{|l|}{$\operatorname{ALT}(\mathrm{U} / \mathrm{l})$} \\
\hline $\begin{array}{c}\text { Grade } 3(>5.0 \text { to } \\
20.0 \times \text { ULN })\end{array}$ & $8 / 626(1.3)$ & $8 / 427(1.9)$ & $11 / 901(1.2)$ & $14 / 918(1.5)$ \\
\hline $\begin{array}{l}\text { Grade } 4 \\
(>20.0 \times \mathrm{ULN})\end{array}$ & $0 / 626$ & $0 / 427$ & $0 / 901$ & $1 / 918(0.1)$ \\
\hline \multicolumn{5}{|l|}{$\operatorname{AST}(\mathrm{U} / \mathrm{l})$} \\
\hline $\begin{array}{c}\text { Grade } 3(>5.0 \text { to } \\
20.0 \times \text { ULN })\end{array}$ & $3 / 626(0.5)$ & $3 / 426(0.7)$ & 6/901 (0.7) & $14 / 917(1.5)$ \\
\hline $\begin{array}{l}\text { Grade } 4 \\
(>20.0 \times \mathrm{ULN})\end{array}$ & $0 / 626$ & $0 / 426$ & $0 / 901$ & $2 / 917(0.2)$ \\
\hline
\end{tabular}


Table 4 continued

\begin{tabular}{|c|c|c|c|c|}
\hline $\begin{array}{l}\text { Parameter, } \\
n / N(\%)\end{array}$ & $\begin{array}{l}\text { PBO } \\
\text { Pooled } \\
N=635 \\
\text { Short-term } \\
\text { data up to } \\
24 \text { weeks }\end{array}$ & $\begin{array}{l}\text { ADA } 40 \text { mg EOW } \\
N=429 \\
\text { Long-term ADA } \\
\text { (monotherapy or in } \\
\text { combination with MTX/ } \\
\text { other csDMARDs) } \\
\text { Mean exposure: } 67 \text { weeks }\end{array}$ & $\begin{array}{l}\text { UPA } 15 \text { mg QD } \\
N=907 \\
\text { Long-term UPA } \\
\text { (monotherapy or in } \\
\text { combination with MTX/ } \\
\text { other csDMARDs) } \\
\text { Mean exposure: } 72 \text { weeks }\end{array}$ & $\begin{array}{l}\text { UPA } 30 \mathrm{mg} \text { QD } \\
N=921 \\
\text { Long-term UPA } \\
\text { (monotherapy or in } \\
\text { combination with MTX/ } \\
\text { other csDMARDs) } \\
\text { Mean exposure: } 71 \text { weeks }\end{array}$ \\
\hline \multicolumn{5}{|l|}{ CPK (U/l) } \\
\hline $\begin{array}{l}\text { Grade } 3(>5.0 \text { to } \\
10.0 \times \mathrm{ULN})\end{array}$ & $4 / 627(0.6)$ & $3 / 426(0.7)$ & $18 / 901(2.0)$ & 26/918 (2.8) \\
\hline $\begin{array}{l}\text { Grade } 4 \\
(>10.0 \times \mathrm{ULN})\end{array}$ & $3 / 627(0.5)$ & $4 / 426(0.9)$ & $8 / 901(0.9)$ & $15 / 918(1.6)$ \\
\hline
\end{tabular}

UPA $15 \mathrm{mg}$ and UPA $30 \mathrm{mg}$ QD groups include patients who were originally assigned to UPA and patients originally assigned to $\mathrm{PBO}$ who switched to UPA at week 24

$A D A$ adalimumab, $A L T$ alanine aminotransferase, $A S T$ aspartate aminotransferase, $C P K$ creatine phosphokinase, csDMARD conventional synthetic disease-modifying antirheumatic drug, $E O W$ every other week, $M T X$ methotrexate, $P B O$ placebo, $Q D$ once daily, $U L N$ upper limit of normal, UPA upadacitinib

monitoring for signs and symptoms of any infection [7].

Recently, reports by regulatory agencies noted that JAK inhibition may increase risk of thrombosis, MACE, malignancy, and mortality [29-31]. Concerns have previously been raised about a potential elevated thromboembolic risk with JAKi treatment [32]. Compared with the general population, patients with PsA have a greater risk of developing MACE or VTE $[33,34]$. An increased risk of MACE and VTE was not observed in our analysis, as the rates of adjudicated MACE and VTE were low and similar across all treatment groups, including placebo. Few patients treated with upadacitinib had a history of VTE $(<3 \%)$, and $9-71 \%$ had various $\mathrm{CV}$ risk factors at baseline. Known risk factors for VTE (higher body mass index, previous VTE, and thrombosis) and MACE (hypertension, smoking, and dyslipidemia) were present in this PsA population. These risk factors were also identified in other JAKi studies [35-37] as well as older age, longer disease duration, history of diabetes mellitus, previous heart failure, and concomitant medication use. Patients receiving upadacitinib who may have an increased risk of thrombosis should be promptly evaluated for signs and symptoms and appropriately treated [7]. Additional robust post-marketing data can help to better understand and characterize the risk of MACE and VTE in patients with PsA receiving JAKi.

Chronic inflammatory autoimmune conditions have been associated with malignancy development [38]. Current literature suggests that PsA may not be associated with an increased overall risk of malignancy [39]. However, limited long-term data are available on malignancy risk in patients with PsA, particularly those treated with JAKi. Although the effects of immunosuppressive agents on malignancy risk remain largely unclear, JAKis are thought to potentially interfere with IFN and T and NK cell function, which play a role in inhibiting tumor cell growth [40]. We found similar malignancy rates across treatment groups, and rates with upadacitinib were comparable with expected rates from the general population. No particular pattern or type of malignancies were observed. Because about one-fifth of patients received upadacitinib for at least 2 years in this analysis, these data should be interpreted with caution. Further longerterm surveillance is needed to evaluate any 

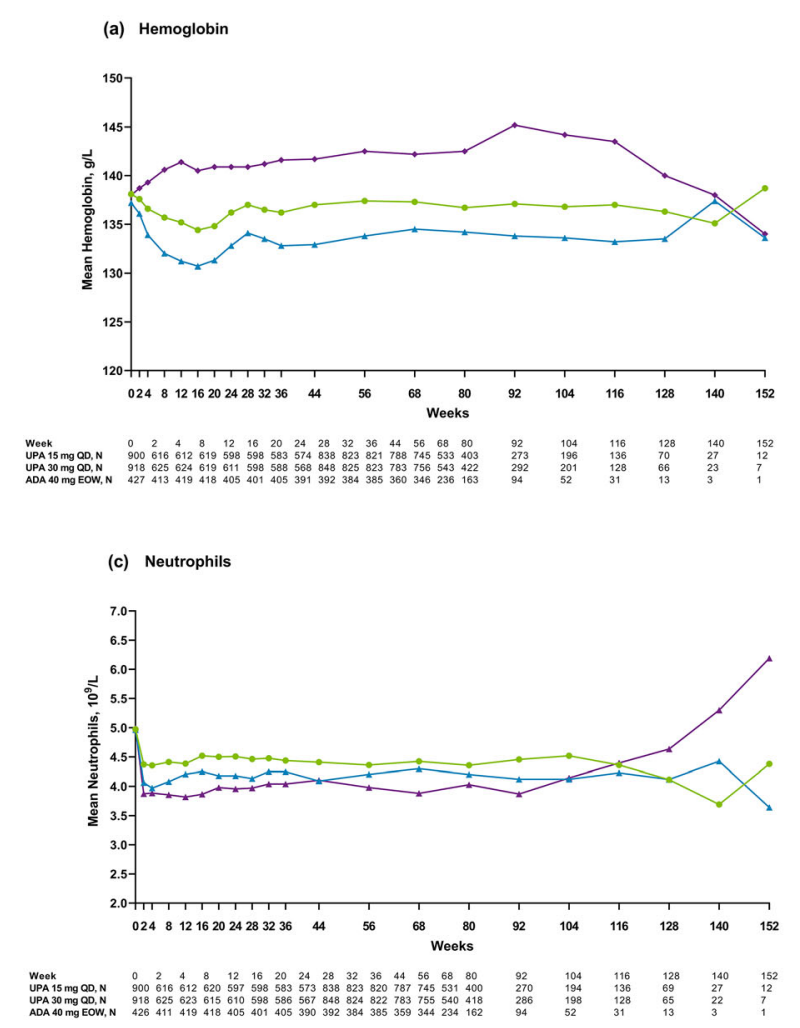

Fig. 2 Mean changes in hemoglobin, platelets, neutrophils, and lymphocytes levels (a-d). Baseline mean includes patients with non-missing baseline and at least

potential malignancy risk with upadacitinib treatment and inform PsA management with JAKi treatment.

Comorbidities of IBD and uveitis have been associated with PsA [41]. However, the rates of IBD and uveitis reported as AEs were low and similar across treatment groups in the SELECTPsA clinical program. Efficacy of upadacitinib in ulcerative colitis was reported in a phase $2 \mathrm{~b}$ trial [42], and a phase 3 clinical program is underway.

A comparative analysis of those receiving upadacitinib with or without MTX suggests that $\mathrm{AE}$ rates were broadly similar among these patient populations, except for numerically higher rates of hepatic disorders and lymphopenia with MTX combination therapy. These findings were not unexpected because MTX use has been associated with an increased risk of liver disease and decreases in lymphocyte count [43, 44]. Monitoring for hepatotoxicity
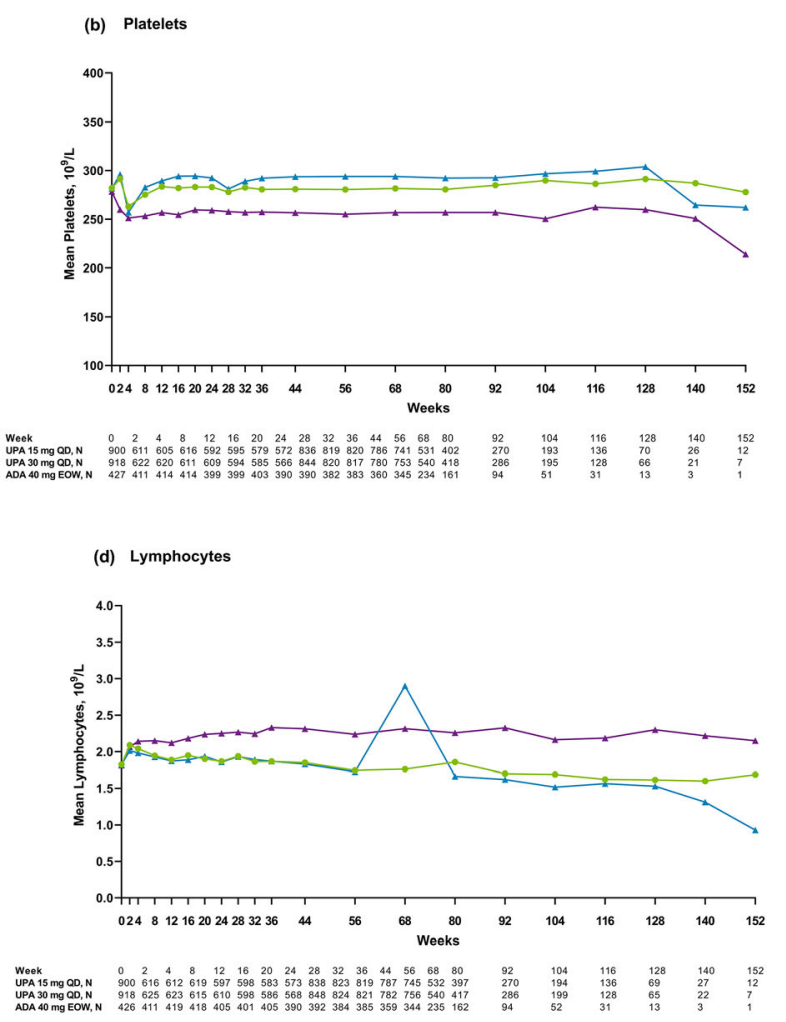

one post-baseline value. $A D A$ adalimumab, $E O W$ every other week, UPA upadacitinib

may be advised for patients with PsA receiving MTX with upadacitinib [45].

Although lab-related AEs were reported, few grade 3 or 4 laboratory abnormalities occurred with either dose of upadacitinib. CPK elevations were more frequent in patients treated with upadacitinib than adalimumab or placebo. Elevated CPK levels have also been observed with other JAKis [46, 47]. Preclinical data on the mechanism behind increased CPK levels suggests that JAK inhibition restores myoblast differentiation [48]. In the SELECT-PsA program, most CPK elevations and other laboratory abnormalities were transient and did not lead to study drug discontinuation. Routine evaluation of laboratory parameters before and during upadacitinib treatment is recommended [7].

Several limitations of this analysis should be acknowledged. Due to the 24-week placebocontrolled portion of the trials, limited safety conclusions compared to placebo can be made 
for events that occur with prolonged exposure to treatment. However, longer-term adalimumab data allowed the safety profile of upadacitinib to be compared with that of a standard of care PsA therapy. Many of the AESIs evaluated were rare, and variations in sample size and exposure time across treatment groups may have introduced bias. Sample size and exposure time were greater for the upadacitinib group versus other treatment groups. This analysis was based on integrated data from two rigorous controlled clinical trials, which may limit the generalizability of the findings to clinical practice. Critical to understanding the benefit-risk profile of PsA therapies, long-term monitoring of patients treated with upadacitinib is ongoing.

\section{CONCLUSIONS}

Based on integrated data from two randomized phase 3 trials of 1828 patients with PsA receiving upadacitinib and 2504.6 PY of exposure, no new or unexpected safety risks emerged with longer-term upadacitinib exposure, consistent with what was observed with upadacitinib in the RA clinical program. Upadacitinib $15 \mathrm{mg}$ and adalimumab had similar safety profiles except for $\mathrm{HZ}$ and opportunistic infections, and the rates of most AEs were higher with upadacitinib $30 \mathrm{mg}$. These results support an acceptable safety profile of upadacitinib $15 \mathrm{mg}$ for the treatment of PsA in patients who had an inadequate response or intolerance to $\geq 1$ nonbiologic or biologic DMARD. The safety of upadacitinib will continue to be monitored in the long-term extensions of the SELECT-PsA trials.

\section{ACKNOWLEDGEMENTS}

AbbVie and the authors thank the patients, study sites, and investigators who participated in these clinical trials.

Funding. AbbVie Inc. (North Chicago, IL, USA) funded this study and participated in the study design, research, analysis, data collection, interpretation of data, reviewing, and approval of the publication. AbbVie Inc. (North Chicago, IL, USA) funded the journal's Rapid Service Fee.

Authorship. All named authors meet the International Committee of Medical Journal Editors (ICMJE) criteria for authorship for this article, take responsibility for the integrity of the work as a whole, and have given their approval for this version to be published.

Author Contributions. AL, RMM, and JL were involved in the acquisition of data. All authors were involved in the analysis and interpretation of the data, drafting the article, and revising it for critically important intellectual content, and approving the final version of manuscript.

Medical Writing, Editorial, and Other Assistance. AbbVie and the authors thank Hannah Palac, Jayesh Patel, and Saeed Motabar, employees of AbbVie Inc., and Bosny J PierreLouis, a former employee of AbbVie Inc., for contributions to statistical analyses, and Julia Zolotarjova, MSc, MWC, an employee of AbbVie Inc., for medical writing support.

Prior Presentation. The main findings of this study were presented in an abstract that was accepted for publication by the European Congress of Rheumatology 2021 in a supplement to the Ann Rheum Dis.

Disclosures. GR Burmester has received consulting fees and speaker honoraria from AbbVie, Eli Lilly, Galapagos, Gilead, and Pfizer. K Winthrop has received consulting fees and/or research grants from AbbVie, AstraZeneca, Bristol-Myers Squibb, Eli Lilly, Galapagos, GlaxoSmithKline, Gilead, Novartis, Pfizer, Regeneron, Roche, Sanofi, and UCB. R Blanco has received grants/research support from AbbVie, MSD, and Roche, and consulting fees/participation in company-sponsored speaker's bureau from AbbVie, Bristol-Myers Squibb, Eli Lilly, Janssen, MSD, Novartis, Pfizer, and Roche. $P$ Nash has received funding for clinical trials, research grants, and honoraria for advice and 
lectures from AbbVie, Amgen, Bristol-Myers Squibb, Celgene, Eli Lilly, Gilead/Galapagos, Janssen, MSD, Novartis, Pfizer, Roche, Samsung, Sanofi, and UCB. $P$ Goupille has received research grants, consulting fees, or speaker honoraria from AbbVie, Amgen, Biogen, BristolMyers Squibb, Boehringer Ingelheim, Celgene, Chugai, Galapagos, Eli Lilly, Janssen, Medac, MSD, Nordic Pharma, Novartis, Pfizer, Sanofi, and UCB. VF Azevedo has received funding for clinical trials, research grants, and honoraria for lectures and advice from AbbVie, Amgen, Bristol-Meyers Squibb, Celltrion, Eli Lilly, GSK, Janssen, Novartis, Pfizer, and UCB. C Salvarani has received consulting fees and research grants from AbbVie, Amgen, Eli Lilly, Novartis, Pfizer, Roche, and Sanofi-Genzyme. A Rubbert-Roth has received honoraria for lectures and consulting fees from AbbVie, Amgen, Bristol Myers-Squibb, Chugai, Eli Lilly, Gilead, Janssen, Novartis, Roche, and Sanofi. EM Ruderman has received consulting fees from AbbVie, Amgen, Bristol Myers-Squibb, Eli Lilly, Gilead, Janssen, Novartis, and Pfizer. E Lesser, R Lippe, RM Mccaskill, and $J$ Liu are employees of AbbVie Inc. and may hold stock or options. A Lertratanakul is a former employee of AbbVie Inc. and may hold stock or options.

Compliance with Ethics Guidelines. The trials were conducted according to the International Conference on Harmonization guidelines, the Declaration of Helsinki principles, and applicable local country regulations. All studyrelated documents were approved by independent ethics committees and institutional review boards at each site (Supplemental Material: Table S2). All patients gave written informed consent.

Data Availability. AbbVie Inc. is committed to responsible data sharing regarding the clinical trials we sponsor. This includes access to anonymized, individual and trial-level data (analysis data sets), as well as other information (e.g., protocols and Clinical Study Reports), as long as the trials are not part of an ongoing or planned regulatory submission. This includes requests for clinical trial data for unlicensed products and indications. This clinical trial data can be requested by any qualified researchers who engage in rigorous, independent scientific research, and will be provided following review and approval of a research proposal and Statistical Analysis Plan (SAP) and execution of a Data Sharing Agreement (DSA). Data requests can be submitted at any time and the data will be accessible for 12 months, with possible extensions considered. For more information on the process, or to submit a request, visit the following link: https://www.abbvie.com/ourscience/clinical-trials/clinical-trials-data-and-in formation-sharing/data-and-information-sharing -with-qualified-researchers.html.

Open Access. This article is licensed under a Creative Commons Attribution-NonCommercial 4.0 International License, which permits any non-commercial use, sharing, adaptation, distribution and reproduction in any medium or format, as long as you give appropriate credit to the original author(s) and the source, provide a link to the Creative Commons licence, and indicate if changes were made. The images or other third party material in this article are included in the article's Creative Commons licence, unless indicated otherwise in a credit line to the material. If material is not included in the article's Creative Commons licence and your intended use is not permitted by statutory regulation or exceeds the permitted use, you will need to obtain permission directly from the copyright holder. To view a copy of this licence, visit http:// creativecommons.org/licenses/by-nc/4.0/.

\section{REFERENCES}

1. Gladman DD, Antoni C, Mease P, Clegg DO, Nash P. Psoriatic arthritis: epidemiology, clinical features, course, and outcome. Ann Rheum Dis. 2005;64(Suppl 2):14-7.

2. Coates LC, Kavanaugh A, Mease PJ, et al. Group for research and assessment of psoriasis and psoriatic arthritis 2015 treatment recommendations for psoriatic arthritis. Arthritis Rheumatol. 2016;68(5): 1060-71. 
3. Singh JA, Guyatt G, Ogdie A, et al. Special article: 2018 American College of Rheumatology/National Psoriasis Foundation guideline for the treatment of psoriatic arthritis. Arthritis Rheumatol. 2019;71(1): $5-32$.

4. Gossec L, Baraliakos X, Kerschbaumer A, et al. EULAR recommendations for the management of psoriatic arthritis with pharmacological therapies: 2019 update. Ann Rheum Dis. 2020;79(6):700-12.

5. Parmentier JM, Voss J, Graff C, et al. In vitro and in vivo characterization of the JAK1 selectivity of upadacitinib (ABT-494). BMC Rheumatol. 2018;2: 23.

6. European Medicines Agency. Upadacitinib summary of product characteristics. 2021. https://www. ema.europa.eu/en/documents/product-information/ rinvoq-epar-product-information_en.pdf. Accessed 6 Apr 2021

7. Food and Drug Administration. Upadacitinib prescribing information. 2019. https://www.access data.fda.gov/drugsatfda_docs/label/2019/211675s0 00lbl.pdf. Accessed 6 Apr 2021

8. Genovese MC, Fleischmann R, Combe B, et al. Safety and efficacy of upadacitinib in patients with active rheumatoid arthritis refractory to biologic disease-modifying anti-rheumatic drugs (SELECTBEYOND): a double-blind, randomised controlled phase 3 trial. Lancet. 2018;391(10139):2513-24.

9. Smolen JS, Pangan AL, Emery P, et al. Upadacitinib as monotherapy in patients with active rheumatoid arthritis and inadequate response to methotrexate (SELECT-MONOTHERAPY): a randomised, placebocontrolled, double-blind phase 3 study. Lancet. 2019;393(10188):2303-11.

10. Fleischmann $\mathrm{R}$, Pangan $\mathrm{AL}$, Song $\mathrm{IH}$, et al. Upadacitinib versus placebo or adalimumab in patients with rheumatoid arthritis and an inadequate response to methotrexate: results of a phase III, double-blind, randomized controlled trial. Arthritis Rheumatol. 2019;71(11):1788-800.

11. van Vollenhoven $\mathrm{R}$, Takeuchi $\mathrm{T}$, Pangan $\mathrm{AL}$, et al. Efficacy and safety of upadacitinib monotherapy in methotrexate-naive patients with moderately-toseverely active rheumatoid arthritis (SELECTEARLY): a multicenter, multi-country, randomized, double-blind, active comparator-controlled trial. Arthritis Rheumatol. 2020;72(10):1607-20.

12. Burmester GR, Kremer JM, Van den Bosch F, et al. Safety and efficacy of upadacitinib in patients with rheumatoid arthritis and inadequate response to conventional synthetic disease-modifying antirheumatic drugs (SELECT-NEXT): a randomised, double-blind, placebo-controlled phase 3 trial. Lancet. 2018;391(10139):2503-12.

13. Mease PJ, Lertratanakul A, Anderson JK, et al. Upadacitinib for psoriatic arthritis refractory to biologics: SELECT-PsA 2. Ann Rheum Dis. 2021;80: 312-20.

14. McInnes IB, Anderson JK, Magrey M, et al. Trial of upadacitinib and adalimumab for psoriatic arthritis. N Engl J Med. 2021;384(13):1227-39.

15. van der Heijde D, Song I-H, Pangan AL, et al. Efficacy and safety of upadacitinib in patients with active ankylosing spondylitis (SELECT-AXIS 1): a multicentre, randomised, double-blind, placebocontrolled, phase $2 / 3$ trial. Lancet. 2019;394(10214):2108-17.

16. McInnes I, Kato $\mathrm{K}$, Magrey $\mathrm{M}$, et al. Long-term safety and effectiveness of upadacitinib in patients with psoriatic arthritis: results at 56 weeks from the SELECT-PsA 1 study. Ann Rheum Dis. 2021;80(Suppl 1):1288-9.

17. Mease PJ, Lertratanakul A, Papp KA, et al. Upadacitinib in patients with psoriatic arthritis and inadequate response to biologics: 56-week data from the randomized controlled phase 3 SELECT-PsA 2 study. Rheumatol Ther. 2021. https://doi.org/10. 1007/s40744-021-00305-z.

18. Cohen SB, van Vollenhoven RF, Winthrop KL, et al. Safety profile of upadacitinib in rheumatoid arthritis: integrated analysis from the SELECT phase III clinical programme. Ann Rheum Dis. 2020;80(3):304-11.

19. Ramiro S, Sepriano A, Chatzidionysiou K, et al. Safety of synthetic and biological DMARDs: a systematic literature review informing the 2016 update of the EULAR recommendations for management of rheumatoid arthritis. Ann Rheum Dis. 2017;76(6):1101-36.

20. Desai RJ, Thaler KJ, Mahlknecht P, et al. Comparative risk of harm associated with the use of targeted immunomodulators: a systematic review. Arthritis Care Res (Hoboken). 2016;68(8):1078-88.

21. Mease PJ, Kavanaugh A, Reimold A, et al. Secukinumab in the treatment of psoriatic arthritis: efficacy and safety results through 3 years from the year 1 extension of the randomised phase III FUTURE 1 trial. RMD Open. 2018;4(2):e000723.

22. Combe B, Rahman $P$, Kameda H, et al. Safety results of ixekizumab with 1822.2 patient-years of exposure: an integrated analysis of 3 clinical trials in adult patients with psoriatic arthritis. Arthritis Res Ther. 2020;22(1):14. 
23. Burmester GR, Curtis JR, Yun H, et al. An integrated analysis of the safety of tofacitinib in psoriatic arthritis across phase III and long-term extension studies with comparison to real-world observational data. Drug Saf. 2020;43(4):379-92.

24. Winthrop KL. The emerging safety profile of JAK inhibitors in rheumatic disease. Nat Rev Rheumatol. $2017 ; 13(4): 234-43$.

25. Choy EH. Clinical significance of Janus kinase inhibitor selectivity. Rheumatology. 2018;58(6): 953-62.

26. Chen Y-H, Chen Y-M, Smolen JS, et al. FRI0164 Incidence rate and characterization of herpes zoster in patients with moderate-to-severe rheumatoid arthritis: an update from baricitinib clinical studies. Ann Rheum Dis. 2019;78(Suppl 2):755.

27. Winthrop KL, Lebwohl M, Cohen AD, et al. Herpes zoster in psoriasis patients treated with tofacitinib. J Am Acad Dermatol. 2017;77(2):302-9.

28. Curtis JR, Xie F, Yang S, et al. Risk for herpes zoster in tofacitinib-treated rheumatoid arthritis patients with and without concomitant methotrexate and glucocorticoids. Arthritis Care Res (Hoboken). 2019;71(9):1249-54.

29. European Medicines Agency. PRAC recommendations on signals. 2021. https://www.ema.europa.eu/ en/documents/prac-recommendation/prac-recomm endations-signals-adopted-7-10-june-2021-prac-mee ting_en.pdf. Accessed 18 Aug 2021

30. Food and Drug Administration. Initial safety trial results find increased risk of serious heart-related problems and cancer with arthritis and ulcerative colitis medicine Xeljanz, Xeljanz XR (tofacitinib). 2021. https://www.fda.gov/media/145590/ download. Accessed 18 Aug 2021

31. Food and Drug Administration. FDA requires warnings about increased risk of serious heart-related events, cancer, blood clots, and death for JAK inhibitors that treat certain chronic inflammatory conditions. 2021. https://www.fda.gov/media/ 151936/download. Accessed 10 Sept 2021

32. Scott IC, Hider SL, Scott DL. Thromboembolism with Janus kinase (JAK) inhibitors for rheumatoid arthritis: How real is the risk? Drug Saf. 2018;41(7): 645-53.

33. Ogdie A, Kay McGill N, Shin DB, et al. Risk of venous thromboembolism in patients with psoriatic arthritis, psoriasis and rheumatoid arthritis: a general population-based cohort study. Eur Heart J. 2017;39(39):3608-14.
34. Ogdie A, Yu Y, Haynes K, et al. Risk of major cardiovascular events in patients with psoriatic arthritis, psoriasis and rheumatoid arthritis: a population-based cohort study. Ann Rheum Dis. 2015;74(2):326-32.

35. Charles-Schoeman C, DeMasi R, Valdez H, et al. Risk factors for major adverse cardiovascular events in phase III and long-term extension studies of tofacitinib in patients with rheumatoid arthritis. Arthritis Rheumatol. 2019;71(9):1450-9.

36. Mease $\mathrm{P}$, Charles-Schoeman $\mathrm{C}$, Cohen $\mathrm{S}$, et al. Incidence of venous and arterial thromboembolic events reported in the tofacitinib rheumatoid arthritis, psoriasis and psoriatic arthritis development programmes and from real-world data. Ann Rheum Dis. 2020;79(11):1400-13.

37. Taylor PC, Weinblatt ME, Burmester GR, et al. Cardiovascular safety during treatment with baricitinib in rheumatoid arthritis. Arthritis Rheumatol. 2019;71(7):1042-55.

38. Franks AL, Slansky JE. Multiple associations between a broad spectrum of autoimmune diseases, chronic inflammatory diseases and cancer. Anticancer Res. 2012;32(4):1119-36.

39. Vaengebjerg S, Skov L, Egeberg A, Loft ND. Prevalence, incidence, and risk of cancer in patients with psoriasis and psoriatic arthritis: a systematic review and meta-analysis. JAMA Dermatol. 2020;156(4): 421-9.

40. Schwartz DM, Kanno Y, Villarino A, Ward M, Gadina M, O'Shea JJ. JAK inhibition as a therapeutic strategy for immune and inflammatory diseases. Nat Rev Drug Discov. 2017;17(1):78.

41. Rida MA, Chandran V. Challenges in the clinical diagnosis of psoriatic arthritis. Clin Immunol. 2020;214:108390.

42. Sandborn WJ, Ghosh S, Panes J, et al. Efficacy of upadacitinib in a randomized trial of patients with active ulcerative colitis. Gastroenterology. 2020;158(8):2139-49.e14.

43. Aithal GP. Hepatotoxicity related to antirheumatic drugs. Nat Rev Rheumatol. 2011;7(3):139.

44. Inokuma S, Kono $\mathrm{H}$, Nakayama $\mathrm{H}$, Yamazaki J. Immunoglobulin and lymphocyte decrease concurrent with adverse reactions induced by methotrexate for RA. Ann Rheum Dis. 2000;59:490.

45. Gelfand JM, Wan J, Zhang $\mathrm{H}$, et al. Risk of liver disease in patients with psoriasis, psoriatic arthritis, and rheumatoid arthritis receiving methotrexate: a population-based study. J Am Acad Dermatol. 2021;84(6):1636-43. 
46. Gladman D, Rigby W, Azevedo VF, et al. Tofacitinib for psoriatic arthritis in patients with an inadequate response to TNF inhibitors. $\mathrm{N}$ Engl J Med. 2017;377(16):1525-36.

47. Smolen JS, Genovese MC, Takeuchi T, et al. Safety profile of baricitinib in patients with active rheumatoid arthritis with over 2 years median time in treatment. J Rheumatol. 2019;46(1):7-18.

48. Queeney K, Housley W, Sokolov J, Long A. FRI0131 Elucidating the mechanism underlying creatine phosphokinase upregulation with upadacitinib. Ann Rheum Dis. 2019;78(Suppl 2):734-5. 